\title{
Organization of remote work in the context of digitalization
}

\author{
Anna Sheveleva,* and Evgeny Rogov \\ Southern Federal University, 344006, Rostov-on-Don, Russia
}

\begin{abstract}
The analysis of the remote work organization indicates the certain reserves in the field of professional activity, manifested in three groups of effects: individual-personal, social-psychological and organizational-managerial. Individual-personal effects are connected with the professional's personality transformation under the influence of professional environment digitalization: a change in the emotional side of the activity, experiencing a lack of information about the colleagues' work, feedback about their role in the overall result. As a result, there appears a fear of missing out; a decrease of analytical thinking and critical perception of professional situations; an increase of physical and psychological fatigue and emotional burnout. Social-psychological effects are due to the peculiarities of interaction in digital technologies conditions, which generates new and modernizes the existing social and cultural communication norms and network etiquette. At online conferences the ratio of visual and auditory components of nonverbal communication changes, the role of listening increases, and there is a greater focus on content in comparison with face-to-face communication. The differences in labor productivity at different communication modes are revealed. Informal interactions, the sense of professional and organizational involvement are reduced. The work-life balance is disturbed. Organizational and managerial effects of remote work are associated with the implementation of labor regulation, control and assessment, staff motivation, forms of employment, organizational membership and commitment, job satisfaction, trust in teams, the composition and structure of work teams, leadership, organization of workplaces and business communications. Many of the organizational factors are closely interconnected.
\end{abstract}

\section{Introduction}

Modern challenges from the digitalization of professional employment and education have recently been intensified by the transfer to remote work, caused by the necessity to follow anti-epidemic rules during the COVID-19 pandemic. This has generated interest of scientific researches to the psychological phenomena that accompany professional activity in such conditions in opposition digitalization of professional employment to the traditional organization of work - with the presence of an employee in the workplace outside the home.

Scientific works have already covered the topics devoted to different forms of

${ }^{*}$ Corresponding author: amsheveleva@sfedu.ru 
employment, organization of work and working conditions [1, 2, 3], digitalization of professional activity [4] and education [5]. Sorensen et al. emphasize the influence of working conditions on the health, well-being and safety of workers, in addition taking into account the impact of the broader context, starting with the conditions at each specific enterprise, including the structure and characteristics of the labor market and considering the wide social, political and economic space [6]. Restrictions connected with the anti-epidemic measures of 2020 and 2021 have raised a new topic in scientific researches. It is related to the organization of remote work of individual employees, teams and enterprises, stress factors of lockdown and coping with them, issues of psychological well-being in lockdown conditions at the level of individuals, labor teams and family groups [7].

Besides the limitations lockdown also gave new opportunities in the field of professional activity. They are connected with the development of technologies, increased digital literacy, new "digital" habits and rituals (in working and out-of-work interaction), new forms of leadership and work autonomy. A. Richter [8] reminds us that it is necessary to distinguish between remote work in lockdown conditions and in normal conditions. In addition, the entry of remote work into the life of society is due to the necessity of employees to organize their own careers. Therefore, in modern conditions, there is a need to analyze the effects of remote work not only from an economic and managerial point of view, but also from the standpoint of psychology.

\section{Methods}

In order to collect comprehensive information about the psychological effects of remote work, the method of literature theoretical analysis was used. The scientific literature in the field of organizational psychology, as well as in the field of management, was analyzed. We analyzed the data of studies on forced remote work organization during the adaptation lockdown period during the COVID-19 pandemic, as well as other organized remote forms of employment in normal stable conditions.

\section{Results}

The generalization of the remote work psychological consequences for individuals and social communities allowed us to distinguish three groups of effects: individual-personal, socialpsychological and organizational-managerial (Fig. 1).

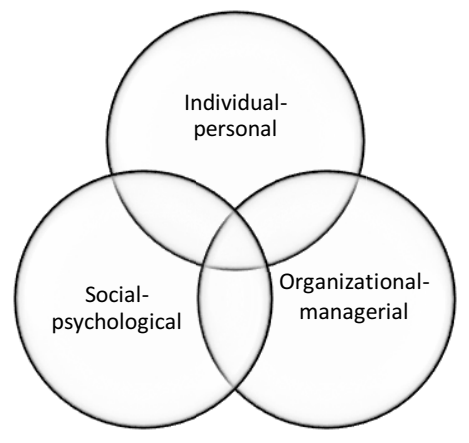

Fig. 1. Groups of psychological effects of remote work

The effects we have generalized relate to different phenomenological manifestations at the level of individuals, small and large groups, are interrelated and may have causal relationships. 
Individual-personal effectsinclude emotional experience, labor motives, features of thinking in stress conditions, individual professional behavior, psychological and somatic health and wellness and burnout. Social-psychological effects include features of communications, interpersonal contacts reduction and social isolation, threat to professional identity, professional values system and work-life balance. Organizational-managerial effects include topics, related to work measuring, assessment, control and monitoring, organizational membership and loyalty, coordination in virtual work teams, selection, recruitment and hiring of employees and self-organizing in conditions of home work-place.

A consistent description of these effects is offered below.

Reyes et al. [20] recommend some of managerial tips for virtual team leaders, following which will help keep productivity facing a challenges of remote work (Table 1).

Table 1. Guide for addressing challenges of transitioning from face-to-face to virtual teams [20]

\begin{tabular}{|c|}
\hline Challenge Recommended actions \\
\hline Continuing to be productive \\
\hline Tip 1: Pre-brief (e.g., daily check-in calls) at the beginning of the work. \\
\hline Tip 2: Manage or avoid emails/calls after the work day is over. \\
\hline Maintaining a shared mental model \\
\hline $\begin{array}{l}\text { Tip 3: Hold daily check-in calls with the whole team so that everyone stays informed } \\
\text { about others' tasks, the current priorities and how it plays into the overall team's } \\
\text { goal. }\end{array}$ \\
\hline $\begin{array}{l}\text { Tip 4: Use an online team project and task management tool for everyone to share } \\
\text { task progress and any other important updates. }\end{array}$ \\
\hline Making team members feel connected to the team and the organization \\
\hline $\begin{array}{l}\text { Tip 5: Continue to have one-on-one calls that are not just related to tasks, based on } \\
\text { individual needs. }\end{array}$ \\
\hline $\begin{array}{l}\text { Tip 6: Create, engage, and encourage fun, non-work related virtual events (e.g., } \\
\text { virtual happy hour) to uplift those who are feeling isolated. }\end{array}$ \\
\hline $\begin{array}{l}\text { Tip 10: Meet with every newcomer individually to have a private, less intimidating } \\
\text { space for them to ask any questions or concerns. }\end{array}$ \\
\hline $\begin{array}{l}\text { Tip 9: Suggest meetings for individuals to meet with one another for smaller } \\
\text { interdependent tasks } \\
\text { members carbon copied (cc'd) to remind them that their work matters. }\end{array}$ \\
\hline Ensuring team members have psychological safety \\
\hline
\end{tabular}

\section{Discussion}

\subsection{Individual-personal effects}

In opinion of N.P. Dedov [4] due to the computerization of work the professional's personality is transformed towards becoming like a computer and reducing the emotional side of activity. However, the emotional component, both negative and positive can be found 
among the effects of remote work. Negative emotions are represented by irritation from fatigue and physical discomfort caused by visual stress and forced static posture, if such regime of work is unusual. Irritation can be also caused by the need to overcome the effects of distraction factors in the home environment. Remote work in video conferencing mode can evoke confusion and dissatisfaction about your own appearance on the screen, objects of furniture seen in the camera and sound interference. As a positive effect of remote work, the reduction in the threat of spoiling the mood when communicating with unpleasant people can be noted. Work in the office sometimes makes such communication forced, while remote work allows you to limit it exclusively to business communications.

Since interaction in remote work is mediated, employees may feel a lack of information about the work of colleagues and the team, feedback about their role in the overall result. That's why «fear of missing out» effect appears. It manifests itself in the form of a fear of not being aware of information or events related to work or making an unequal (usually smaller) contribution in comparison with the other employees to the common business. This effect is compensated by the desire to be always in touch, even during non-working hours.

Limited information, "invisibility" of the subjects of interaction can cause negative effects - a decrease in analytical thinking and critical perception of professional situations, nonnormative professional behavior [9].

The peculiarities of labor motivation in remote work are manifested in an increase of the role of intrinsic motivation and self-control of employees. Limitations on the managers and supervisors ability to control work make extrinsic motivation less effective.

Among the individual and personal effects of remote work, one can note physical and psychological fatigue and emotional burnout, health risks, especially for vision, the lack of the need to move to and from work, which provides the opportunity for distraction and motor activity although it takes time and other resources.

\subsection{Social-psychological effects}

When working remotely, interaction becomes mediated by technical devices and digital technologies. As a result - the peculiarities of employees' communication, both inside and outside the teams. In this regard, new social and cultural norms of communication, rituals and network etiquette have appeared and are being clarified. In particular, sometimes unsatisfactory communication conditions and sound quality in video conferences allow us to give a recommendation not to hesitate to ask again, since the "loss" of separate words and phrases can negate mutual understanding. Moreover, the "microphone rule", when the microphone is turned on only for the speaker in order to avoid sound interference, contributes to the implementation of the etiquette prohibition to interrupt the interlocutor, since each statement is preceded by a minimum, but a pause to turn on your own microphone and a conscious effort to perform this action. Therefore, the number of impulsive talks in online meetings is reduced. According to A. Richter [8] in the context of video conferences, communications become more focused on content, and the demonstration of status and power goes away from interactions compared to face-to-face meetings.

The technical environments in which communications take place determine the psychological specifics of these communications. In particular, in online meetings, the role of listening increases, a number of visual non-verbal components of communication fall out, it is difficult to track the audience's attention, and sometimes you have to speak looking at your own image on the screen, which is unusual compared to normal conditions. G. Itzchakov, J. Grau [10] give recommendations for reducing undesirable effects: pay more attention to the expressiveness of the voice, apply different forms of group discussions (in writing or in small groups), use the settings of the technique that allow the speaker to be visible to the interlocutors, but not to himself. Besides, it is recommended to use additional 
visual signals, for example, presentations for the effectiveness of online conferences.

N. Grözinger et al. [11] point to differences in the effectiveness of oral and written communication in teams. It was found that communication via chat leads to a decrease in innovations compared to face-to-face communication. Productivity is higher in teams with video conferencing than in teams with chat.

The reduction of formal and informal contacts of employees during remote work in comparison with working in the physical presence conditions causes a sense of isolation, separation of teams, and a decrease in the employee' identification with the organization and profession. Since positive informal interactions in the team are one of the factors of cohesion, it is necessary to rely on this factor even in the conditions of remote work. After analyzing different forms of social support from the professional online community effectiveness, A. Ihl et al. [12] concluded that emotional social support increases group identification and a sense of involvement, while instrumental support does not affect involvement.

The decrease of informal contacts at work has its positive side, as mentioned above. The benefits are shown in the case of a negative relationship or a low focus on communication. The limitation of contacts to business necessity is beneficial then.

Remote work provides great opportunities for building a career in accordance with personal preferences. These opportunities are associated with professional mobility, flexibility and combination of work, multiple organizational memberships. But the downside of career individualization is that the senses of professional belonging and organization loyalty are at risk [9]. The involvement of employees working remotely is lower compared to the employees of the main office [3].

The psychological effects of remote work affect the value component of professional activity, both at the level of individuals and at the level of social groups. According to M.V. Zinnatova, E.V. Lebedeva [9] there may be a "decline in the value of the real professional world" at the individual level. There is not always mutual understanding about the value of professional work and working hours of people working outside and from home at the family level. The underestimation of employment and an overestimation of the availability of a person if he/she is at home appears. The change in the attitude to the status of some professions as more or less important has happened at the level of society, as a result of antiepidemic measures and lockdown [13].

The most important aspect of the social-psychological effects of remote work can be called the blurring of the boundaries between personal and professional life and their worklife balance $[1,3,14,15,16,17]$. More recently, remote work was considered as an opportunity to find this balance. But as the remote work became forced, went through a period of adaptation and in some cases showed its economic feasibility, it began penetrating the lives of more and more people. Then there appeared the contrasting expression "worklife separation", indicating not only the combination, but also the problem of separation between different sets of social roles. The role conflict can cause emotional stress. There are two options in the experience of this role conflict - "work interferes family" and "family interferes work". The manifestation of one of them depends on the dominance of family or professional needs of a person. For example, blurred role boundaries are more likely to be more disruptive for employees with family needs [14].

The factors that aggravate and smooth out the conflict between work and personal life are identified. Aggravating factors include a large number of responsibilities in both areas [18], noise from other family members, helping children, household chores, the availability of a remote employee for other family members who consider it possible to interrupt him, the presence of family memorable events [15]. The remote work has increased gender inequality in the violation of the boundaries between family and professional life. Women were more at risk because they traditionally have more household chores, parent responsibilities, and monitoring their children's education [16]. 
Factors that smooth out conflict are: additional time for the family by saving time for transportation, increased flexibility in dealing with family needs and greater control over work tasks that meet these needs, reduced stress due to the physical and psychological distance between work and home, decrease of distracting communication with colleagues [15].

Since satisfaction with the work-life balance is an individual matter, it is possible to note the resources that contribute to this satisfaction. This is an income and a subjective assessment of professional skills level [18], the ability to negotiate and manage the boundaries between family and work, the distribution of involvement in work and household chores in families with two working spouses [14], organization factors. Describing the latter, E.J. Hill et al. [1] and V.J. Morganson et al. [3] showed that there are differences in the subjective assessment of the work-life balance by employees in different forms of work organization. The highest rating is given by people who work at home (without coordination with their work partners in real time), and the average rating is given by office employees. Remote work in the virtual office mode (with real-time coordination of work activities with other employees or partners) is most often associated with experiencing an imbalance and less success in personal/family life.

\subsection{Organizational-managerial effects}

Such effects of remote work are connected with the organization of labor regulation, control and assessment, staff motivation, forms of employment, organizational membership and commitment, job satisfaction, trust in teams, the composition and structure of work teams, leadership, organization of workplaces and business communications. Many of the organizational factors have multiple relationships among themselves - for example, increased stress at work can cause decrease in job satisfaction, which in its turn can lead to lower productivity [7]. Therefore, the revealing of organizational and managerial effects has applied meaning and forms the basis of recommendations for managerial implications.

The problem of control is one of the main ones, it is especially actual in the case of insufficiently psychologically autonomous employees. In addition, control is associated not only with the assessment of the quality of work, but also encourages employees. Thus, $\mathrm{N}$. Jensen et al. revealed that regular remote monitoring with feedback increases the productivity of employees. The mechanism of action here is as follows: employees know that their results are valued and considered, their satisfaction with work and, as a result, productivity increases. No impact of monitoring without feedback on labor productivity was found [19].

The problem of keeping the integrity of the team is the second in importance. It is closely connected with communication, interpersonal relationships and the attitude of employees to the organization, the strategy of team selection. In the context of remote work, virtualization of business communications allows people to work without being geographically tied to the location of the organization. At the same time, such career opportunities allow an employee to combine membership in several organizations, which can reduce his or her sense of belonging to an organization or team. Decreased organizational commitment and feeling of isolation can also be the result of reduced informal communication between employees. Therefore, the main focus of recommendations for managerial implications is aimed at establishing a balanced mode of communication with employees. Such a mode should combine, if possible, online and face-to-face meetings, team and individual communication, formal and informal communication, regular informing of employees about tasks and achievements, encouragement of employees' initiative and joint leadership [8, 20, 21]. The effectiveness of virtual interaction is increased by using online team coordination tools to share task progress and important updates. It is recommended to hold informal virtual events to reduce the feeling of isolation and raise the mood [20]. In order to keep the integrity of the 
team and corporate culture, remote techniques of social support and team building are being developed, and managers are encouraged to be informally interested in the work of employees [10].

T. L. Rapp, A. A. Rapp [22] recommend applying a selection strategy for hiring employees that takes into account the ability to be independent, self-organized and teamoriented to reduce the problems associated with the control and lack of loyalty of employees.

Recommendations for solving the problem of trust to the manager, the team and the organization are related to ensuring the transparency of the audit and expert decision-making, and to the regularity and transparency of the audit. Trust is also positively affected by the possibility of personal contacts with employees and the manager [21,22].

Among organizational and managerial effects one can emphasize those that manifest themselves in the self-organization of their own remote work. Since the main problem is related to the blurring of the boundaries between work and personal life, at first it is recommended to manage these boundaries for its prevention. This is time management - for example, to avoid the temptation of checking work mail during non-working hours, and to respect the personal time of employees. This is, if possible, the territorial separation of the working place from the places of eating, sleeping, resting, and playing.

\section{Conclusion}

The COVID-19 pandemic has served as a catalyst for the development of remote forms of employment and their impact on the psychological state of individuals and groups. On the basis of the theoretical analysis the individual-personal, social-psychological and organizational-managerial psychological effects of remote work showing additional opportunities and limitations of such work organization were generalized and analyzed. Many of the described factors are closely interrelated and can also cause some contradictions between the professional and personal intentions of the subject. The elimination of dissonance requires the creation of conditions that allow overcoming departmental barriers, integrating various individually personal, social-psychological and organizationalmanagerial effects. Due to this, the psychological effects caused by remote work have their own representation in management practice, which explains the applied importance of their research.

\section{References}

1. E.J. Hill, M. Ferris, V. Martinson, Journal of Vocational Behavior 63 (2), 220-241 (2003). https://www.semanticscholar.org/paper/Does-it-matter-where-you-work-Acomparison-of-how-Hill-Ferris/5168f72cdb9d912a920b54efdf511e3640d96f9a

2. A.A. Krasnolutskiy, Scientific journal 7 (30), (2018). https://cyberleninka.ru/article/n/motivatsionnyy-komponent-otnosheniya-k-rabotesotrudnikov-s-raznymi-vidami-trudoustroystva.

3. V.J. Morganson, D.A. Major, K.L. Oborn, J.M. Verive, M. Heelan, Journal of Managerial Psychology 25, 578-595 (2010).

4. N.P. Dedov, Akmeology 3 (67), (2018). https://cyberleninka.ru/article/n/pozitivnyemehanizmy-regulyatsii-professionalnoy-deyatelnosti-v-usloviyah-tsifrovizatsiiobschestva.

5. L.M. Andryukhina, N.O. Sadovnikova, S.N. Utkina, A.M. Mirzaahmedov, The Education and Science Journal 3(22), 116-147 (2020). doi: 10.17853/1994-5639-20203-116-147 
6. G. Sorensen, J.T. Dennerlein, S.E. Peters, E.L. Sabbath, E.L. Kelly, G.R. Wagner, Social Science \& Medicine 269, 113593 (2021). doi.org/10.1016/j.socscimed.2020.113593.

7. V. Venkatesh, International Journal of Information Management 55, 102197 (2020). doi.org/10.1016/j.ijinfomgt.2020.102197.

8. A. Richter, Locked-down digital work, International Journal of Information Management 55, 102157 (2020). doi.org/10.1016/j.ijinfomgt.2020.102157.

9. M.V. Zinnatova, E.V. Lebedeva, Insight 1 (1), (2020). https://cyberleninka.ru/article/n/k-probleme-preventsii-destruktivnogo-

professionalnogo-razvitiya-lichnosti-v-usloviyah-tsifrovizatsii

10. G. Itzchakov, J. Grau, Organizational Dynamics. 100820 (2020) doi.org/10.1016/j.orgdyn.2020.100820.

11. N.Grözinger, B.Irlenbusch, K.Laske, M.Schröder, Journal of Economic Behavior \& Organization 180, 201-218 (2020) doi.org/10.1016/j.jebo.2020.09.009.

12. A. Ihl, K.S. Strunk, M. Fiedler, Computers in Human Behavior 113, 106482 (2020). doi.org/10.1016/j.chb.2020.106482.

13. A. Kramer, K.Z. Kramer, Journal of Vocational Behavior 119, 103442 (2020). doi.org/10.1016/j.jvb.2020.103442.

14. E. Cho, Journal of Vocational Behavior 119, 103437 (2020). doi.org/10.1016/j.jvb.2020.103437.

15. T.D. Golden, Organizational Dynamics. $100822 \quad$ (2021). doi.org/10.1016/j.orgdyn.2020.100822.

16. E.E. Kossek, K.-H. Lee, Organizational Dynamics. 100818 (2021). https://doi.org/10.1016/j.orgdyn.2020.100818.

17. S.L.D. Restubog, A.C.G. Ocampo, L. Wang, Journal of Vocational Behavior 119, 103440 (2020). doi.org/10.1016/j.jvb.2020.103440.

18. I.A. Monakhova, Ekonomicheskaya sotsiologiya 17 (1), 30-61 (2016).

19. N. Jensen, E. Lyons, E. Chebelyon, R. Le Bras, C.Gomes, Journal of Economic Behavior and Organization 176, 489-511 (2020). doi.org/10.1016/j.jebo.2020.05.010.

20. D.L. Reyes, M. Luna, E. Salas, Organizational Dynamics 100785 (2020)..doi.org/10.1016/j.orgdyn.2020.100785.

21. S.A. Newman, R.C. Ford, Organizational Dynamics. 100802 (2020)doi.org/10.1016/j.orgdyn.2020.100802.

22. T.L. Rapp, A.A. Rapp, Organizational Dynamics. 100821 (2021). doi.org/10.1016/j.orgdyn.2020.100821. 